\title{
Ring current intensification and convection-driven negative bays: Multisatellite studies
}

\author{
X.-Y. Zhou, ${ }^{1}$ B. T. Tsurutani, ${ }^{1}$ G. Reeves, ${ }^{2}$ G. Rostoker, ${ }^{3}$ W. Sun, ${ }^{4}$ J. M. Ruohoniemi, ${ }^{5}$ \\ Y. Kamide, ${ }^{6}$ A. T. Y. Lui, ${ }^{5}$ G. K. Parks, ${ }^{7}$ W. D. Gonzalez, ${ }^{8}$ and J. K. Arballo ${ }^{1}$ \\ Received 3 February 2003; revised 28 July 2003; accepted 27 August 2003; published 22 November 2003.
}

[1] The original view on the cause of ring current intensifications was a frequent occurrence of intense substorm expansion phases. Results from many studies have supported this view. However, whether this is the only mechanism of ring current buildup has been a controversy. Kamide [1992] asserted that ring current intensification is due to "sustained, southward IMF, not because of frequent occurrence of intense substorms." Lui et al. [2001] have shown that the ring current can be intensified during enhanced convection without substorm occurrence. Tsurutani et al. [2003] have found that there was a lack of substorm expansion phases for long periods of time (up to 7 hours) in 5 out of 11 storm main phases (in 1997) that were induced by the smoothly varying $B_{z}$ component of the interplanetary magnetic field (IMF) within interplanetary magnetic clouds. In this paper, a relatively weak magnetic storm event (with minimum SYM-H at $-47 \mathrm{nT}$ ) that occurred on 15 July 1997 is studied using ground-based magnetograms, polar cap potentials from Super Dual Auroral Radar Network, and Los Alamos National Laboratory (LANL) geosynchronous energetic particle data as well as the Polar UV imaging (for aurorae) and Wind (for the solar wind) data. It is shown that during the storm main phase, there was a lack of substorm expansion phase activity (from imaging and the groundbased data) and a lack of energetic particle injections at the geostationary orbit. The most prominent auroral forms were north-south aligned auroral patches and torches. Dawn and dusk aurorae were more intense than the aurorae near midnight, where auroral gaps occurred. In addition, this paper shows that there was a significant directly driven activity during the storm main phase when the IMF was continually southward. We argue that during this event the ring current intensification was more strongly associated with enhanced magnetospheric convection than with impulsive energy unloading. Three scenarios are suggested to explain the relatively low intensity of the magnetic storm induced by a magnetic cloud. They are (1) weak nightside auroral zone ionospheric ion outflows (due to lack of substorms), (2) choked penetration of the tail plasma flow (due to lack of substorms), and (3) retarded magnetospheric convection (due to reduced solar wind-magnetosphere reconnection). The observed saturation of the polar cap potential drop is in support of this latter mechanism. INDEX TERMS: 2788 Magnetospheric Physics: Storms and substorms; 2778 Magnetospheric Physics: Ring current; 2784 Magnetospheric Physics: Solar wind/magnetosphere interactions; 2716 Magnetospheric Physics: Energetic particles, precipitating; 2704 Magnetospheric Physics: Auroral phenomena (2407); KEYWORDS: ring current intensification, magnetic storm, storm-substorm relationship, auroras during storm and substorms, solar wind-magnetosphere coupling

Citation: Zhou, X.-Y., et al., Ring current intensification and convection-driven negative bays: Multisatellite studies, J. Geophys. Res., 108(A11), 1407, doi:10.1029/2003JA009881, 2003.

\footnotetext{
${ }^{1}$ Jet Propulsion Laboratory, California Institute of Technology, Pasadena, California, USA.

${ }^{2}$ Los Alamos National Laboratory, Los Alamos, New Mexico, USA.

${ }^{3}$ Department of Physics, University of Alberta, Edmonton, Alberta, Canada.
}

Copyright 2003 by the American Geophysical Union. 0148-0227/03/2003JA009881

\footnotetext{
${ }^{4}$ Geophysical Institute, University of Alaska, Fairbanks, Fairbanks, Alaska, USA.

${ }^{5}$ Applied Physics Laboratory, Johns Hopkins University, Laurel, Maryland, USA.

${ }^{6}$ Solar-Terrestrial Environment Laboratory, Nagoya University, Toyokawa, Japan.

${ }^{7}$ Space Science Laboratory, University of California, Berkeley, Berkeley, California, USA.

${ }^{8}$ Instituto Nacional de Pesquisas Espaciais (INPE), São Paulo, Brazil.
} 


\section{Introduction}

[2] A southward turning of the interplanetary magnetic field (IMF) is thought to enhance dayside magnetic reconnection that causes enhanced magnetospheric convection and a buildup of magnetic energy in the magnetotail. During long intervals of southward IMF the solar wind energy is transferred into the magnetosphere continually through dayside magnetic reconnection. It has been suggested that the release of excess energy in the tail then takes place through transient and frequent substorm expansions, and/or through a "quasi-steady" magnetospheric convection as open field lines are reconnected across the distant tail neutral sheet and are convected into the inner magnetosphere leading to ring current development.

[3] A substorm expansion phase is known to be "initiated on the nightside of the Earth in which a significant amount of energy derived from the solar wind-magnetosphere interaction is deposited in the auroral ionosphere and magnetosphere" [Rostoker et al., 1980]. Substorm expansions are high-latitude, transient (1 to a few hours) phenomena of which more than $50 \%$ are triggered by abrupt changes in the IMF [McPherron et al., 1986]. However, some substorm expansion phases can also occur under strong steady loading processes [Hones, 1979; Baker et al., 1990, 1999]. A magnetic storm is primarily characterized by a main phase during which "a sufficiently intense and long-lasting interplanetary convection electric field $\left(E_{y}\right)$ leads to an intensified ring current sufficiently strong to exceed some key threshold of the quantifying storm-time Dst index" [Gonzalez et al., 1994]. Magnetic storms are long-lived phenomena (several hours to a few days) which feature a ring current that penetrates to low L-shells close to the Earth $(L \sim 3-5)$. It is thought [cf. Russell et al., 1974] that a storm main phase can develop only when the IMF $B_{z}$ is southward and exceeds a certain threshold level. Gonzalez and Tsurutani [1987] and Tsurutani et al. [1988] have shown a one-to-one relationship between intense southward IMF and magnetic storms during the 1978-1979 solar maximum era. A magnetic storm is considered to be "major" when Dst $<-100 \mathrm{nT}$, which generally occurs when IMF $E_{y}>5 \mathrm{mV} \mathrm{m}^{-1}$ for at least 3 hours. Although ring current intensification has been attributed to the integration of intense and frequent substorm expansion phases [Akasofu, 1968], different arguments have been posed for many years, such as ring current intensification is due to long-lasting and intense southward IMF instead of frequent occurrence of intense substorms [Burton et al., 1975; Gonzalez et al., 1989; Kamide, 1992]. Rostoker [2000] suggested that the crosstail current contributes significantly to Dst during storm time. Lui et al. [2001] and Tsurutani et al. [2003] have shown that the ring current can be intensified without substorm expansion phase occurrence.

[4] On the basis of Akasofu's [1964] definition, a classic substorm expansion phase in the UV aurora is expected to be an auroral brightening onset near midnight at the lowest latitude region of the auroral oval. The brightened aurora has "poleward, westward and eastward expansions within 5 to 30 min." These features were not detected in the nightside auroral zone during some ring current intensification events induced by magnetic clouds [Tsurutani et al.,
2003] and by steady magnetospheric convection [Sergeev et al., 2001]. What were detected in both studies were northsouth aligned auroral patches or torches that often connected a high-latitude $\left(\sim 70^{\circ}-72^{\circ}\right)$ auroral band to a lower latitude $\left(\sim 65^{\circ}\right)$ band. The two bands have been called a double oval [Elphinstone et al., 1995a, 1995b]. These patches extended $\sim 1$ hour in local time (longitudinal width) by $\sim 5^{\circ}$ in latitude and had durations of $\sim 3$ to $6 \mathrm{~min}$. Similar north-south oriented auroral arc structures have been discussed by Rostoker et al. [1987], Nakamura et al. [1993], Henderson et al. [1995, 1998], and Sergeev et al. [1999]. Sergeev et al. [2001] have found similar auroral structures (to that shown by Tsurutani et al. [2003]), which occurred during southward IMF. They also noted that there were no large-scale (substorm related) plasma sheet particle injections for these events. Henderson et al. [1995] suggested that "the formation of north-south aligned structures may be related to the bursty bulk flows (BBFs)." Later on, there were more studies of the auroral emissions and magnetotail bursty bulk flows (BBFs) [e.g., Henderson et al., 1998; Sergeev et al., 1999; Sandholt and Farrugia, 2001; Nakamura et al., 2001].

[5] The events studied by Tsurutani et al. [2003] were interplanetary magnetic cloud events, which have the properties of low plasma beta, smooth north-south (or south-north) magnetic field rotations, and a general absence of Alfvén waves [Klein and Burlaga, 1982; Tsurutani et al., 1988; Farrugia et al., 1997]. It is the latter two qualities that are of importance here. Such smooth IMF $B_{z}$ rotations and the lack of $B_{z}$ fluctuations (discontinuities) will not provide abrupt interplanetary/ magnetospheric electric field changes that might be necessary in general for substorm expansion phase triggering [Tsurutani and Meng, 1972; Meng et al., 1973; Perreault and Akasofu, 1978; Iyemori, 1980; Rostoker et al., 1982; McPherron et al., 1986; Kan et al., 1988; Lyons, 1995; Lyons et al., 1997; Russell, 2000]. On the other hand, Pytte et al. [1978] have found that a continuous southward IMF may drive a convection bay which is characterized by weak and infrequent substorms during intense geomagnetic disturbances (with $A E$ at $\sim 500-1000 \mathrm{nT}$ ) in the nightside auroral zone.

[6] It was also noted in the Tsurutani et al. [2003] events that the storms were of lower intensity (less negative in Dst) than usual when there was a lack of substorm expansion phases during storm main phases. They suggested that substorms may play an important role in the heating and acceleration of ionospheric oxygen ions, and that without continuous supplement of ionospheric ions into the nearEarth plasma sheet, the storm-time ring current could be diminished. In contrast, Sergeev et al. [2001] have concluded that geomagnetic activity during convection bay events was not necessarily of lower intensity.

[7] In this paper, the ring current intensification during the 15 July 1997 storm will be studied from several aspects: (1) auroral forms observed by the Polar UVI, which will be compared with the aurorae that occurred during a classical substorm expansion phase, (2) magnetospheric convection observed with ground-based magnetometers and the Super Dual Auroral Radar Network (SuperDARN) radars, and (3) energetic particle injections at the geosynchronous orbit. 


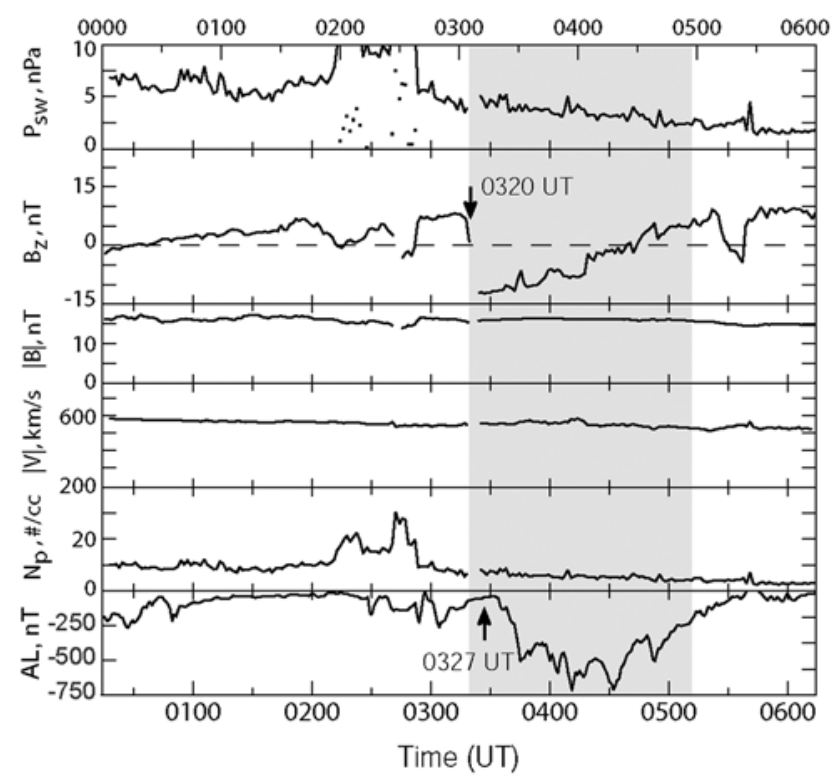

Figure 1. Solar wind parameters and $A L$ geomagnetic index for the 23 September 1999 substorm expansion phase event. The solar wind data have been shifted $14 \mathrm{~min}$. The time at the top is UT at the Wind spacecraft. The shaded area is a duration for which the auroral activity is shown in Figure 2.

All three are important aspects for the study of substorm expansion phases and ring current intensifications, and therefore, for the storm-substorm relationship.

\section{A Classical Substorm Expansion Phase Identified Using Polar UVI}

[8] Classical substorm expansion phases have been described by Akasofu [1964] based on auroral observations made from the ground. The most salient features include that in the first $0-5$ min the equatorwardmost arc brightens. Then over the next 5-10 min, the region of brightening auroral arcs expands rapidly poleward, westward, and eastward. In the following 10-30 min, the aurora reaches the northernmost point. After this expansion phase, the arcs reform and drift back to their presubstorm latitudes in 30 min to 1 hour. During intervals of strong activity, the above procedure can take place in 5-10 min [Akasofu, 1964]. It is these auroral expansion signatures and sequence that will be examined in this paper using the Polar UV imager.

[9] On 22 September 1999, an intense interplanetary shock was detected at $\sim 1209$ UT at the Wind spacecraft. This shock triggered a storm sudden commencement at 1222 UT, which was followed by an intense magnetic storm with minimum SYM-H at $-166 \mathrm{nT}$ at $2300 \mathrm{UT}$. Figure 1 shows the Wind observations and the geomagnetic $A L$ index during 0000-0600 UT on 23 September 1999. The top five panels show the solar wind parameters, and the bottom panel shows the geomagnetic $A L$ index. $A L$ is provided by the World Data Center for Geomagnetism at Kyoto University, Japan. The solar wind data have been shifted by 14 min to take into account the time delay of the solar wind propagation from Wind to the nose of the magnetopause $\left(X=10 R_{E}\right)$. The time at the top of the figure is the time in UT at Wind (before shifting). For comparison with auroral variations, the shifted time (bottom of figure) will be used in this paper hereafter. The shaded interval is the duration from which the Polar UV imaging data will be shown later (in Figure 2). The arrow at $0327 \mathrm{UT}$ in the $A L$ panel indicates a substorm expansion phase onset, which was detected by the Polar UV instrument. This substorm expansion phase may have been triggered by the sharp IMF $B_{z}$ southward turning at $\sim 0320$ UT.

[10] The Polar UVI images shown in Figure 2 were obtained using the Lyman-Birge-Hopfield (LBH) longwavelength filter centered at $\sim 170 \mathrm{~nm}$ [Torr et al., 1995]. Each image is shown in geomagnetic local time coordinates with magnetic local noon at the top and dawn on the right. The north magnetic pole is at the center. Circles for the magnetic latitudes are shown at $10^{\circ}$ intervals from $80^{\circ}$ to $50^{\circ}$. The temporal sequence is from the left to right, then down to the next row. Although there are higher time resolution ( $\sim 37$ s) Lyman-Birge-Hopfield long filter (LBHL) data for this event, we show images at $\sim 4$-min cadence to conserve space. In the images from 0320:22 to 0452:59 UT, the brightening in the noon sector from $50^{\circ}$ to $\sim 70^{\circ}$ magnetic latitude (MLAT) is due to dayglow and should be ignored.

[11] At the beginning of this interval the whole auroral oval was quiet as shown by the first two images, although the minimum SYM-H index was at $-146 \mathrm{nT}$ at the early storm recovery phase. SYM-H was $\sim-120 \mathrm{nT}$ at the end of the period shown in Figure 2. Some quiescent auroral arcs existed in the sector of 0000-0300 magnetic local time (MLT). A sudden auroral brightening occurred between 0324:03 and 0327:44 UT at $\sim 60^{\circ}$ MLAT near local midnight in the region of $\sim 2200-0000$ MLT, which is a typical substorm expansion phase onset location [Elphinstone et al., 1995c]. The image at 0324:40 UT (not shown here) shows that auroral intensification started from midnight at $\sim 60^{\circ}$ MLAT, which was the equatorward boundary of the midnight auroral oval at this moment. The aurora had significant poleward, westward, and eastward expansions within $\sim 13 \mathrm{~min}$ (from 0325 UT). At 0338:46 UT, the auroral poleward edge reached $\sim 67^{\circ}$ MLAT, the western edge reached $\sim 2100$ MLT, and the eastern edge reached $\sim 0300$ MLT. After $\sim 15 \mathrm{~min}$ from $0338 \mathrm{UT}$, at $\sim 0353 \mathrm{UT}$, the auroral brightening was $\sim 4 \mathrm{kR}$ with the polewardmost aurora at $\sim 71^{\circ}$ MLAT, and a 9-hour longitudinal coverage from $\sim 1900$ MLT through the midnight sector to $\sim 0400$ MLT. Near 2300 MLT, the auroral poleward expansion speed was $\sim 750 \mathrm{~m} \mathrm{~s}^{-1}$ on average in $0325-0353 \mathrm{UT}$. The auroral brightness decayed after 0353 UT, but the auroral area continued to expand until $\sim 0420$ UT. At $\sim 0511$ UT, after $\sim 1$ hour and 20 min from the brightening maximum, the nightside auroral oval recovered to a state that was as quiet as before the auroral expansion onset. The timing of the auroral evolution and the auroral expansion characteristics shown in Figure 2 are the same as what have been described by Akasofu [1964]. We therefore conclude that this midnight auroral evolution is an auroral substorm event that clearly includes expansion and recovery phases.

[12] It should be noted that this isolated substorm expansion phase (with minimum $A L$ at $\sim-720 \mathrm{nT}$ ) did not lead to a global auroral intensification. The aurora was mainly confined to the nightside auroral oval, especially in 

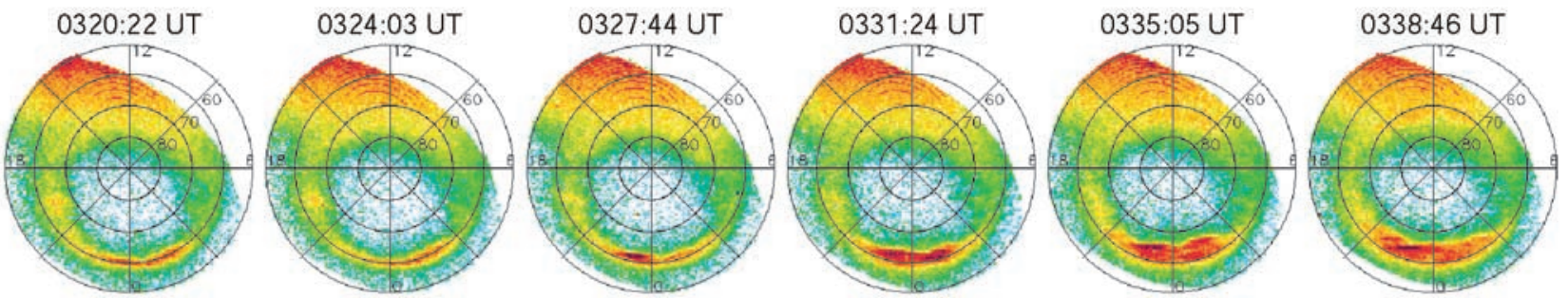

0342:27 UT

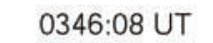

0349:48 UT
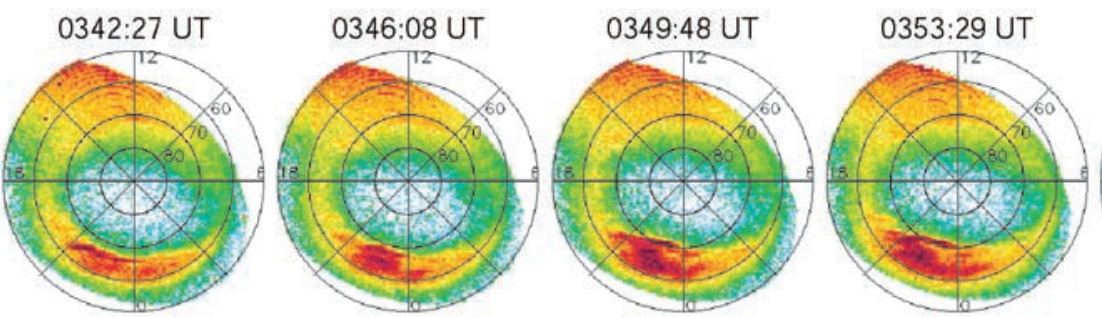

0357:10 UT
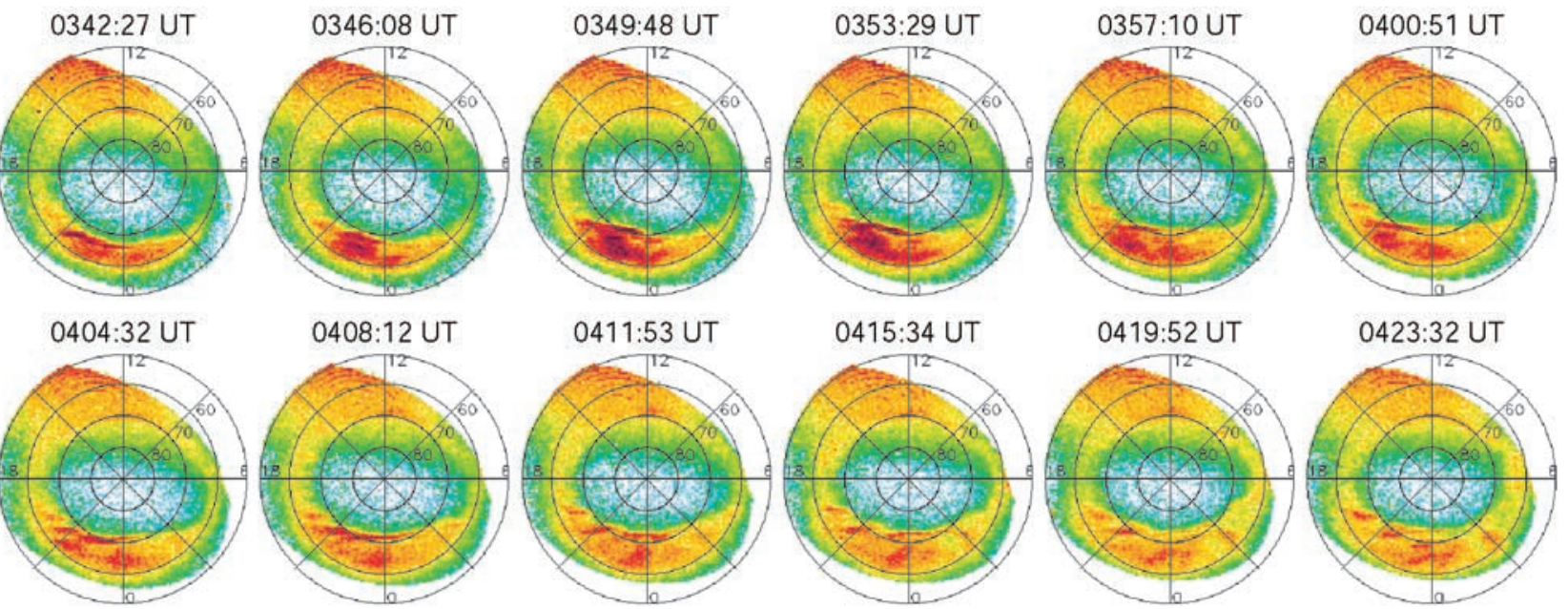

0419:52 UT

0423:32 UT
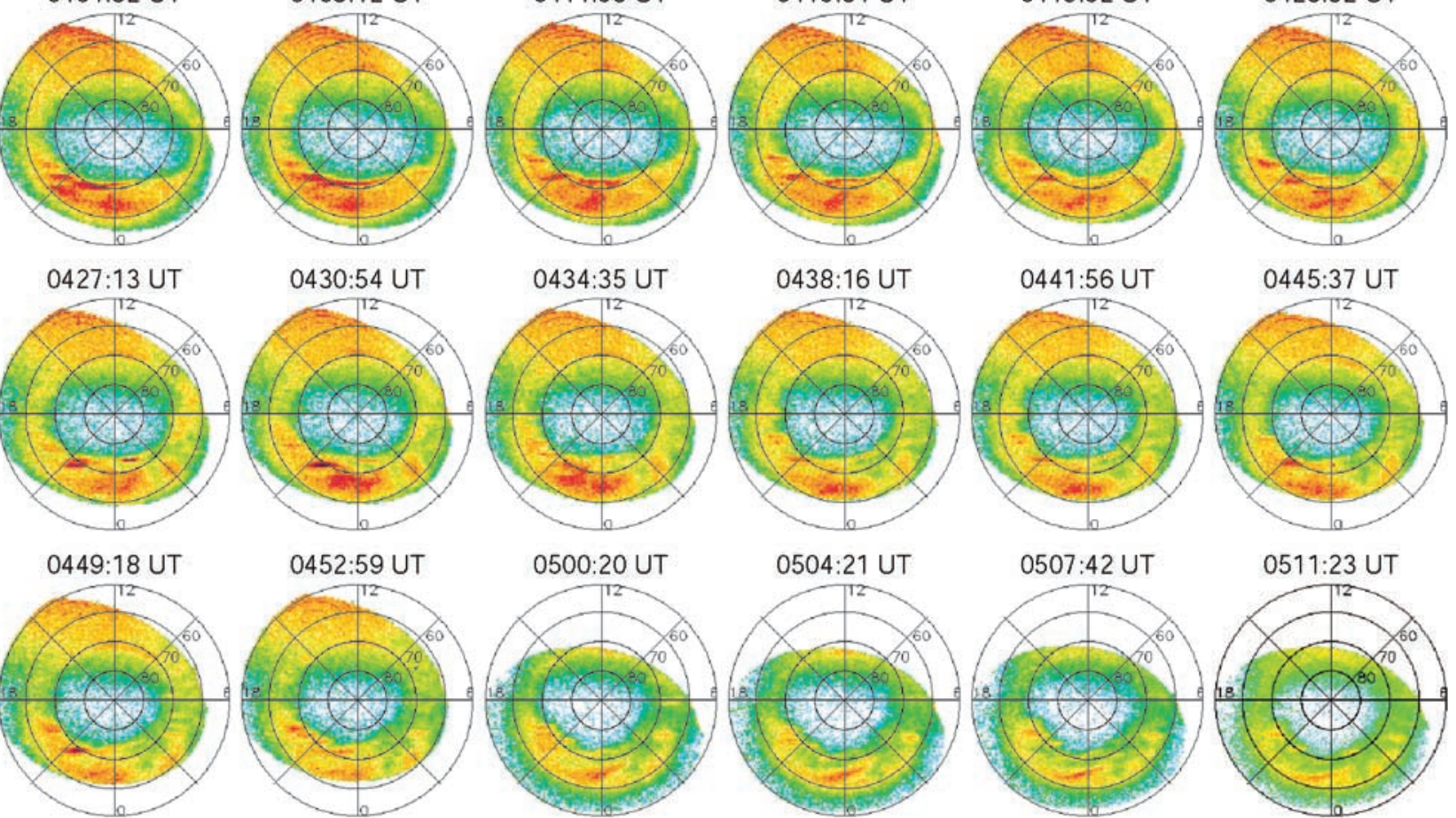

0500:20 UT

0504:21 UT
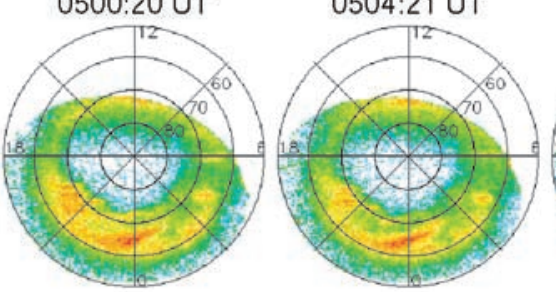

0507:42 UT
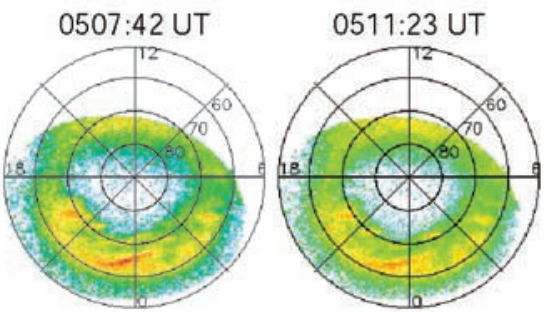

POLAR UVI LBHL

September 23, 1999

0.1 1.0

Figure 2. A classical substorm expansion detected by the Polar UV imager on 23 September 1999. Images are shown in geomagnetic local time coordinates. In each image, magnetic local noon is at the top and dawn is on the right. The temporal resolution is $\sim 4 \mathrm{~min}$.

the midnight sector (2100-0300 MLT). Auroral patches can be seen after 0400 UT, especially in the premidnight region near 2100 MLT. The patches had a north-south orientation with some east-west extent (e.g., in the image at 0423:32 UT, the patch in 1900-2000 MLT was observed from $\sim 62^{\circ}$ to $68^{\circ}$ MLAT, and in 2100-2200 MLT another spanned from $\sim 64^{\circ}$ to $71^{\circ}$ MLAT).

[13] This substorm expansion phase appears in $A L$ (see Figure 1) as a significant decrease from $\sim-40 \mathrm{nT}$ at 0332 UT to $\sim-510 \mathrm{nT}$ at $0344 \mathrm{UT}$, during which the maximum auroral poleward expansion occurred in the
2100-0000 MLT sector from $\sim 63^{\circ}$ to $69^{\circ}$ MLAT. This development in the $A L$ index occurred $\sim 5$ min after the expansion onset detected by the Polar UVI, which implies that during this event the current flow in the wedge took $\sim 5$ min to become large enough to produce a magnetic perturbation. The $A L$ index decreased to a minimum of $-716 \mathrm{nT}$ at $\sim 0410$ UT when there was a further poleward expansion to $\sim 72^{\circ}$ near midnight (seen in the images from 0404:32 to 0411:53 UT). Another $A L$ minimum of $-711 \mathrm{nT}$ occurred at 0431 UT when an auroral intensification and poleward expansion were detected in the UV data during 


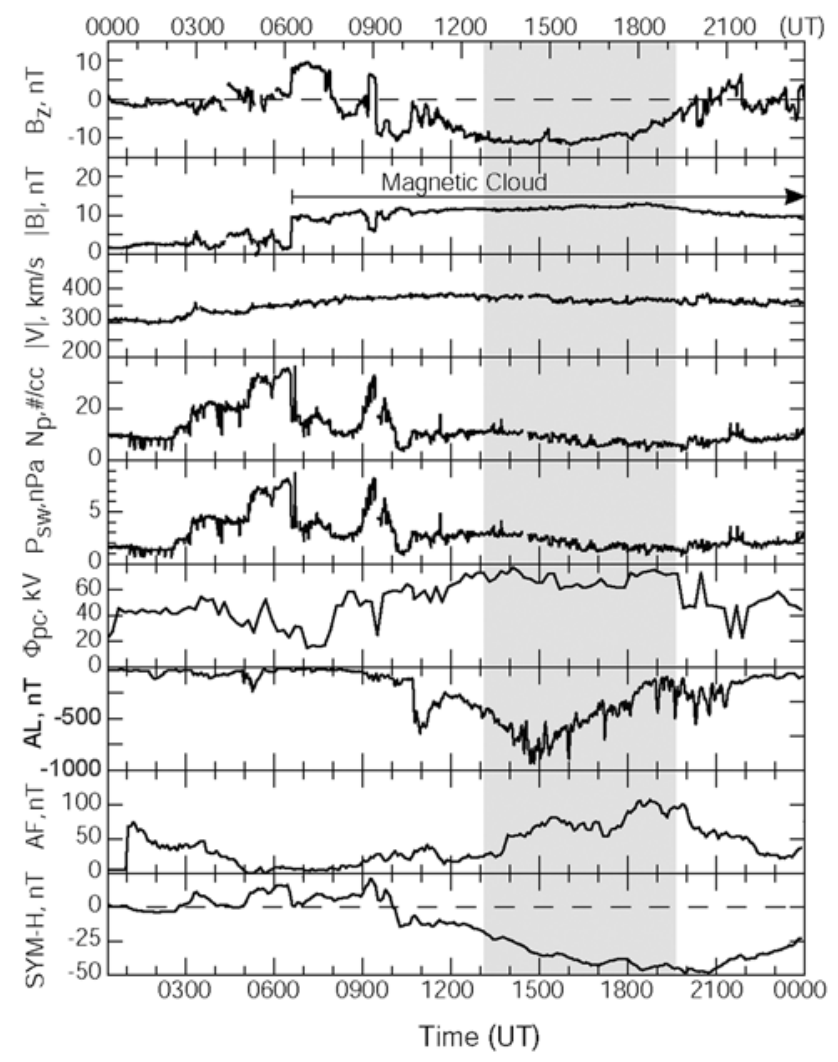

Figure 3. Solar wind and ground observations for the 15 July 1997 magnetic storm event. The solar wind data have been shifted $23 \mathrm{~min}$. The time at the top is UT at the Wind spacecraft. The shaded area is a duration for which the auroral activity is shown in Figure 4.

$\sim 0427-0431$ UT. It is obvious that the Polar UV imaging data enable the identification of substorm expansion phases as well as the related geomagnetic disturbances that are seen in the $A L$ index or other ground-based magnetograms. Actually, the imaging data are superior since the auroral images show not only the onset time of the substorm expansion phase but also the location, which one cannot expect to infer from the $A L$ index. Akasofu [1964] had based his original definition on auroral images and still holds to this concept today (S. Akasofu, personal communication, 2002).

\section{Ring Current Intensifications When Substorm Expansion Phases Are Lacking}

[14] In this section, we will discuss a magnetic storm event during which there were no substorm expansion phases during the ring current intensification. This magnetic storm was induced by a magnetic cloud that occurred on 15 July 1997 and is shown in Figure 3. The Wind observations (shown in the top five panels) are the IMF $B_{z}$ component, the IMF magnitude, the solar wind speed, the proton density, and the solar wind ram pressure $\left(\rho V^{2}\right)$. A time delay (23 $\mathrm{min}$ ) from the Wind spacecraft to the nose of the magnetopause has been used to shift the solar wind parameters. The time at the top is the unshifted UT at Wind. The duration when the Polar UV imaging data were available is again indicated by the shading. The magnetic cloud is indicated in the $|\mathrm{B}|$ panel and is characterized by a plasma $\beta$ lower than 0.1. During the passage of the magnetic cloud, the IMF was southward at $\sim-11 \mathrm{nT}$ from $\sim 1300$ to 1700 UT. The solar wind dawn-dusk electric field $E_{y}$ was $\sim 4.0 \mathrm{mV} \mathrm{m}^{-1}$ within this interval.

[15] Shown in the panels of Figure 3, below the solar wind parameters, the ground-based observations are the polar cap electric potential drop $\left(\Phi_{\mathrm{pc}}\right)$, the $A L, A F$, and SYM-H indices. The $\Phi_{\mathrm{pc}}$ is obtained from the SuperDARN radar observations. $A F$ is a new geomagnetic index that monitors the field-aligned currents using the geomagnetic $Y$ components observed at a number of midlatitude ground stations. It has been found that the $A F$-Dst correlation is 20.7-0.8 [Sun and Akasofu, 2000]. Sun and Akasofu [2002] have also shown that the $A F$ index is well correlated with the energetic neutral atom (ENA) emission, for which increases are very well correlated with ring current intensifications regardless of whether there are substorm expansion phases [Jorgensen et al., 1997, 2001; Lui et al., 2001].

[16] As shown in Figure $3, \Phi_{\mathrm{pc}}$ was higher than $50 \mathrm{kV}$ throughout the storm main phase. From 1200 to 1940 UT, $\Phi_{\mathrm{pc}}$ was higher than $60 \mathrm{kV}$ when the IMF $B_{z}$ was about $-10 \mathrm{nT}$. This is also the interval of the ring current buildup. The $A L$ index features a behavior characteristic of convection bays with $A L$ decreasing from $\sim-10 \mathrm{nT}$ at $\sim 0800 \mathrm{UT}$ to $-910 \mathrm{nT}$ at $1445 \mathrm{UT}$ and gradually recovering thereafter. In order to understand the sudden increase in the $A L$ index at $1045 \mathrm{UT}$, the magnetograms from the stations in the midnight sector (the Alaska and Canadian Auroral Network for the OPEN Program Unified Study (CANOPUS) magnetometer chains) have been examined and will be discussed later. The result shows that the $H$ components suddenly decreased $\sim 200 \mathrm{nT}$ at 1045 UT, which implies the occurrence of a small substorm that could have been triggered by the IMF northward turning from -8 to $-1 \mathrm{nT}$ as shown in the top panel. At this time, when this small substorm occurred, $\Phi_{\mathrm{pc}}$ decreased, and the SYM-H index increased slightly, which is consistent with the substormtriggering picture of Lyons et al. [2001]. The $A F$ index generally increased during the ring current intensification when the magnetospheric convection was intense. This increase indicates an ENA flux enhancement (i.e., an increase in the total ring current ion population from $\sim 0930$ to 2030 UT). Actually, the Polar ENA observations show that there was a clear enhancement during the storm main and recovery phases. The $A F$ and $A E$ indices were not correlated very well during this event.

[17] The Polar UV images within a 6-hour interval (1310-1934 UT) on 15 July 1997 are shown in Figure 4. The images were obtained using the LBH long-wavelength filter with the same format as in Figure 2. The images are shown at $\sim 8$-min cadence to save space. The highest time resolution $(\sim 37$ s) LBHL images were used to create an animation to examine the auroral dynamics during the ring current intensification.

[18] During the first 2 hours (1310-1510 UT) of the imaging interval, when $A L$ decreased, the auroral brightening was intense, above $2 \mathrm{kR}$, along the entire oval within the Polar UVI field of view. Many north-south oriented auroral patches and torches, as described by Henderson et al. [2002], were seen to develop. Those north-south aurorae in the postmidnight region appeared to drift toward dawn 


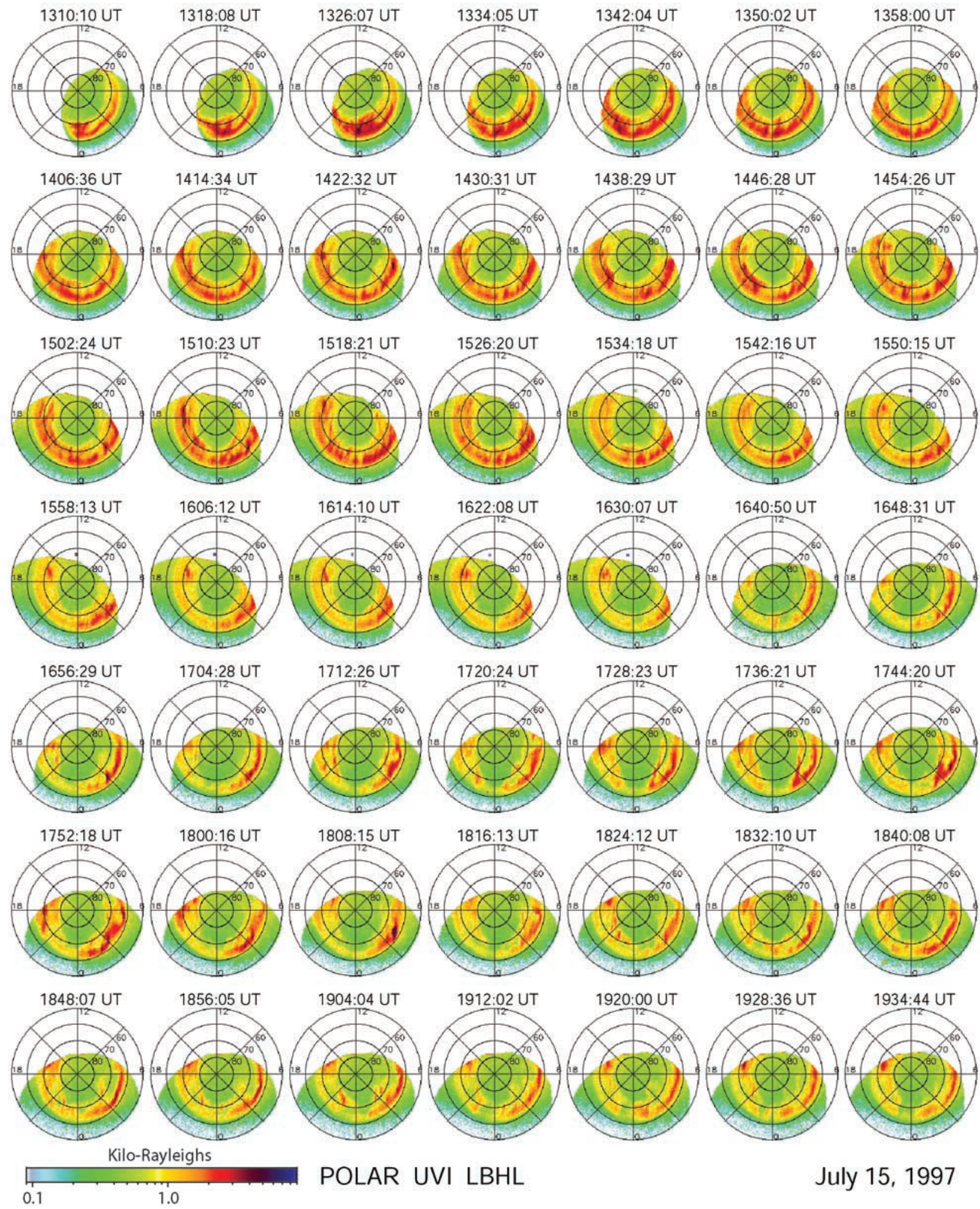

Figure 4. UV aurorae observed by the Polar UVI within the magnetic storm main phase on 15 July 1997. This figure has the same format as Figure 2 . The time resolution is $\sim 8 \mathrm{~min}$.

(which can be seen clearly from the auroral animation). This auroral dawnward drifting is in the same direction as the energetic electron gradient and curvature drifting in the magnetosphere, from the nightside plasma sheet to dayside magnetosphere through dawn. After $\sim 1500 \mathrm{UT}$, when $A L$ reached the minimum, the auroral torches decayed in brightness and size. Aurorae in the midnight-dawn sector were brighter than in the midnight-dusk sector, and the 


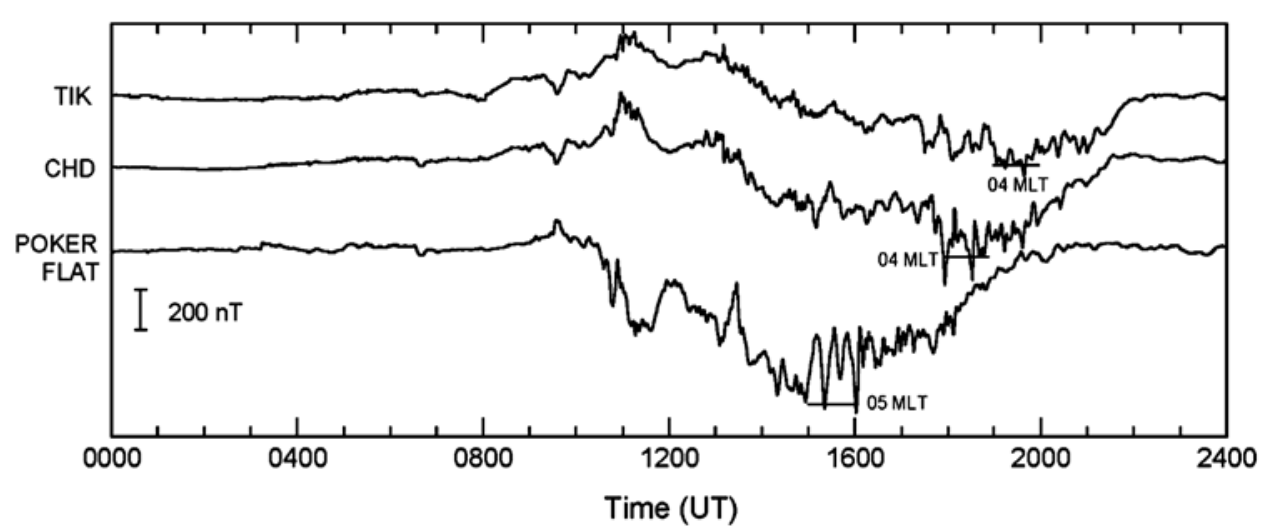

Figure 5. Geomagnetic $X$ component stack plot of the 15 July 1997 event. The ground-based magnetometers are at TIK $\left(66^{\circ}, 197^{\circ}\right)$ geomagnetic coordinates, CHD $\left(65^{\circ}, 212^{\circ}\right)$, and Poker Flat $\left(66^{\circ}\right.$, $261^{\circ}$ ), respectively.

latitudinal width of the auroral oval started to decrease in the midnight sector. Consequently, an auroral gap (same as the gap reported by Lui et al. [1995] and Chua et al. [1998]) appeared from $\sim 1700 \mathrm{UT}$. The gap covered an MLT range from $\sim 2200$ MLT to midnight. Gradually, this gap moved eastward and covered a range of $\sim 0000-0140$ MLT at $\sim 1740$ UT. Then an auroral loop filled in this gap in the 0000-0300 MLT sector, which can be seen in the image at 1752:18 UT. The auroral loop drifted eastward at a speed $\sim 1.5 \mathrm{~km} \mathrm{~s}^{-1}$ with the center at $\sim 0300$ MLT in the 1800:16 UT image and at $\sim 0500$ MLT in the 1816:13 UT image. At $\sim 1930$ UT, another auroral gap occurred near midnight with a coverage from $\sim 2230$ to 0030 MLT. This gap existed until $\sim 2000$ UT, the end of the imaging data. For a more detailed description of auroral forms during the storm main phases when substorm expansion phases were lacking, interested readers can refer to Tsurutani et al. [2003].

[19] Data from ground-based magnetometers and geosynchronous satellites have been examined as well to identify possible substorm expansion phases during the ring current intensification. Figure 5 shows a stack plot of the geomagnetic field $X$ component from two stations of the $210 \mathrm{MM}$ chain, TIK $\left(66^{\circ}, 197^{\circ}\right)$, and $\operatorname{CHD}\left(65^{\circ}, 212^{\circ}\right)$ [Yumoto et al., 1996, 2001], and one Alaska station, Poker Flat $\left(66^{\circ}, 261^{\circ}\right)$, in geomagnetic coordinates. The three stations are approximately at the same magnetic latitude. A westward electrojet was detected by Poker Flat at $\sim 1045$ UT as the station was at $\sim 0100$ MLT. A few minutes later, the CHD and TIK magnetometers detected an eastward electrojet. This electrojet activity is believed to involve the same process reflected in the sudden decrease in $A L$.

[20] From 1300 to 2000 UT when there were UVI data available, TIK and CHD were at $\sim 2200-0600$ MLT, while the Poker Flat station was at $\sim 0300-1000$ MLT. During this time, the signatures in the magnetograms were very similar to the magnetic negative bay that is characterized by long duration negative variations in the $X$ component, which are most intense in the morning sector [Pytte et al., 1978]. In Figure 5, the $X$ component for all stations decreased to a minimum when the stations were in the dawn sector (i.e., TIK and CHD reached the $X$ minimum at $\sim 0400$ MLT, and Poker Flat at $\sim 0500 \mathrm{MLT})$. The total decreases during the negative bay were $\sim 400,600$, and $800 \mathrm{nT}$ at TIK, CHD, and Poker Flat, respectively. From 1200 to 2000 UT there were no obvious substorm expansion phases observed by these magnetometers.

[21] The energetic particle data from the Los Alamos National Laboratory (LANL) geosynchronous satellites are available for the duration of the ring current intensification and the data from spacecraft 1994-084 are shown in Figure $6 \mathrm{a}$ (the energetic proton flux) and Figure $6 \mathrm{~b}$ (the energetic electron flux). At about 1047 UT, spacecraft 1994084, located near dusk (1800 MLT), observed a dispersed proton injection signature, and spacecraft 1990-095, located near dawn (0830 MLT), observed a dispersed electron injection signature (not shown here) consistent with an injection somewhere on the nightside between the two spacecrafts. During the time from 1300 to 2000 UT, while LANL 1994-084 was passing through the midnight sector from 2000 to 0300 MLT, there were no dispersionless injections of the type commonly associated with substorm expansion onsets [e.g., Reeves et al., 1997; Liou et al., 2001]. Perhaps there was no significant dipolarization of the tail magnetic field as well. Some short durations and moderate injections, such as at $\sim 1330,1500$, and 1800 UT in the proton flux, are similar to the narrow injections previously identified to be the inner-magnetospheric continuations of the plasma sheet BBFs [e.g., Sergeev et al., 1999]. These bursty flows had a very short timescale and were not very effective in populating the inner magnetosphere [Sergeev et al., 1998] but may be related to the auroral patches and torches.

[22] Correlations between the polar cap potential drop $\Phi_{\mathrm{pc}}$ and the solar wind dawn-dusk electric field $E_{y}$ and between $\Phi_{\mathrm{pc}}$ and the indices $A U$ and $|A L|$ were examined, and the results are shown in Figure 7 . The best linear fit of the data is described at the top of each panel. Figure $7 \mathrm{a}$ shows that for higher values of $E_{y}\left(>3.2 \mathrm{mV} \mathrm{m}^{-1}\right)$ only elevated values $(>50 \mathrm{kV})$ of potential drop were recorded. Below this value of $E_{y}$, the potential varied over a wide range $(\sim 15-75 \mathrm{kV})$. The solution for the potential drop is conditioned somewhat by the use of a statistical convection model keyed to the IMF, as described by Ruohoniemi and Baker [1998] and Shepherd and Ruohoniemi [2000], but the variability in potential for fixed IMF must arise from the variability in the direct measurements of the convection electric field. Although in this case the coverage of the 


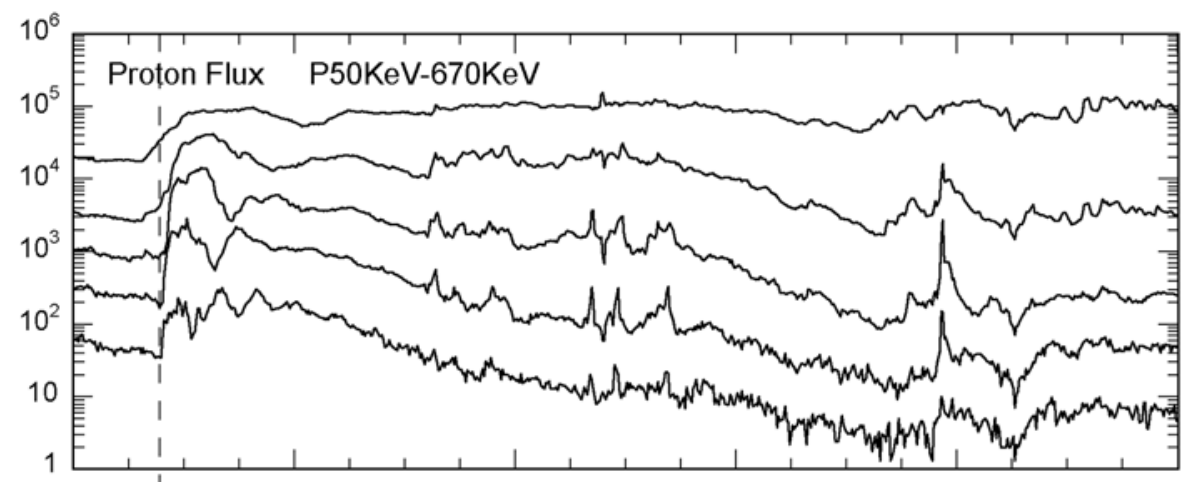

(a)

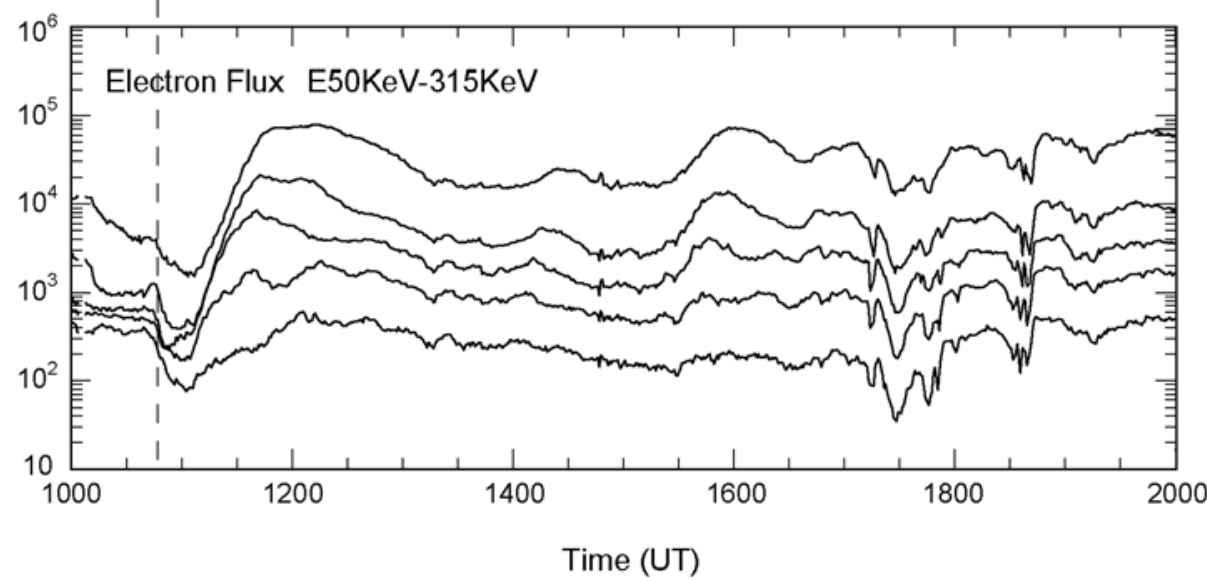

(b)

Figure 6. LANL 1994-084 high energetic (a) proton and (b) electron flux data for the 15 July 1997 event.

potential pattern by SuperDARN varied considerably over the 24-hour period, the observations remained consistent with only limited expansion of the auroral oval and a moderate increase in potential drop. Figure $7 \mathrm{~b}$ shows the correlation of the potential with the $A U$ index. The scatter is reduced from that of the earlier plot, indicating a somewhat higher correlation of the potential with eastward electrojet enhancements. Figure 7c shows that the correlation of the potential with westward electrojet enhancements is not as good as that for the eastward electrojet. This is because the value of $A L$ presenting westward electrojet is controlled more by conductivity, while the value of $A U$ presenting eastward electrojet variability is mainly controlled by the electric field [Ahn et al., 1999]. Furthermore, the radar
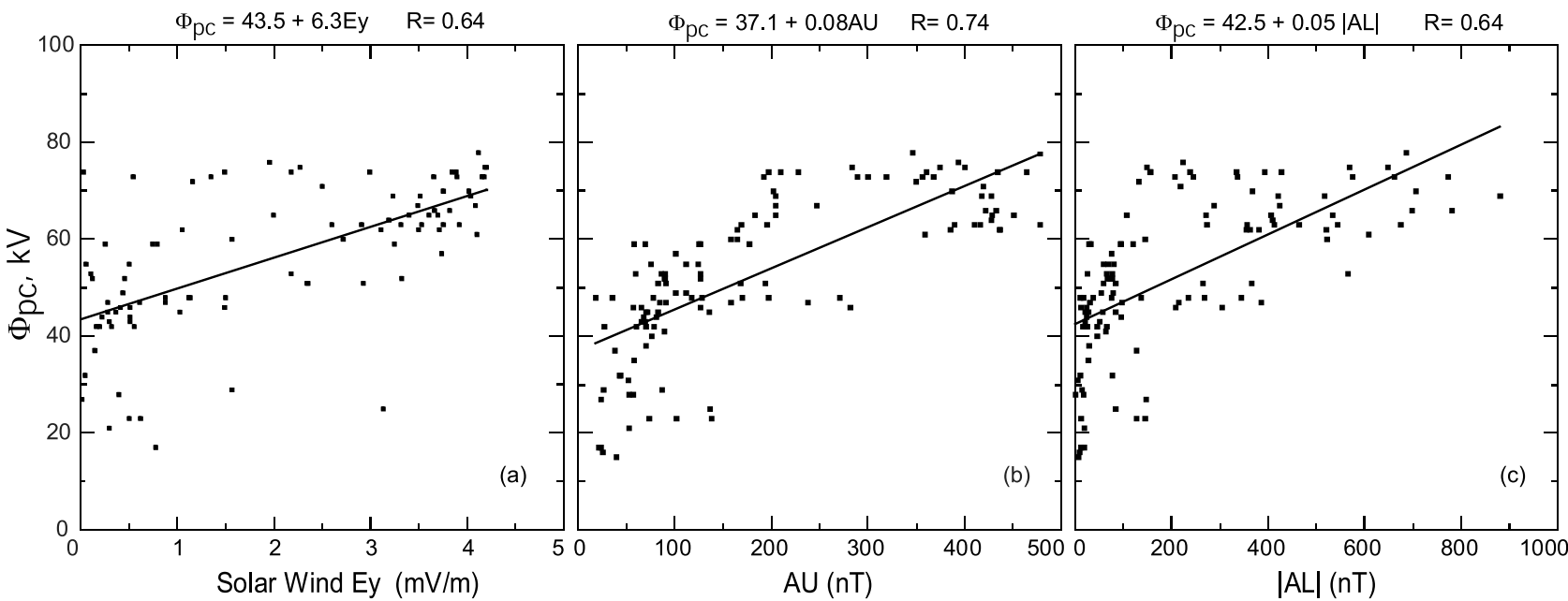

Figure 7. Polar cap potential drop $\Phi_{\mathrm{pc}}$ during the 15 July 1997 event. Data used in this figure are the relevant data shown in Figure 3. (a) The $\Phi_{\mathrm{pc}}$ as a function of the solar wind dawn-dusk electric field $E_{y}$. $E_{y}$ was calculated based on the solar wind parameters, $E_{y}=V B_{s}$. (b) Correlation between $\Phi_{\mathrm{pc}}$ and the $A U$ index. (c) Correlation between $\Phi_{\mathrm{pc}}$ and the $A L$ magnitude. 
velocity measurements are insensitive to conductivity variations. In Figure 7c, $\Phi_{\mathrm{pc}}$ appears to saturate at $|A L| \geq 150$ $\mathrm{nT}$, which will be discussed later. Again, the variability is more obvious for more quiescent conditions with $\Phi_{\mathrm{pc}}$ varied over a range of $\sim 60 \mathrm{kV}$ from $\sim 15$ to $75 \mathrm{kV}$ when $A U$ and $|A L|$ were lower than $\sim 150 \mathrm{nT}$. This uncertainty may suggest that there is some time delay involving the response of the ionosphere to the external environment.

\section{Why is the 15 July 1997 Magnetic Storm Weak?}

[23] We have presented a magnetic storm that was caused by an interplanetary magnetic cloud event during which the IMF $B_{z}$ was southward and smooth for longer than 10 hours. During the storm main phase, the $E_{y}$ was $4.0 \mathrm{mV} \mathrm{m}^{-1}$ for $\sim 6$ hours and the SYM-H minimum was at $-47 \mathrm{nT}$. Russell et al. [1974] found that when the solar wind $E_{y}$ is $\sim 1.5 \mathrm{mV} \mathrm{m}^{-1}$, Dst is roughly at $-25 \mathrm{nT}$, and when $E_{y}$ is $\sim 2.5 \mathrm{mV} \mathrm{m}^{-1}$, Dst is at about $-60 \mathrm{nT}$. Thus the intensity of the 15 July 1997 storm is quite low. Tsurutani et al. [2003] have shown that for magneticcloud-induced storms, the intensity is often low. Here we discuss three possible reasons for the low intensities of these magnetic storms. First, the ionospheric ion outflow might be weak during this event. More than 30 years ago, Akasofu [1968] claimed that Magnetic Storm $=\Sigma$ Magnetospheric Substorm. The reason that provoked Akasofu for this assertion was his belief that substorms are associated with the increase of the proton (of energies $<50 \mathrm{keV}$ ) density in the trapping region. Therefore "if substorms occur frequently enough, these protons tend to accumulate in the trapping region and form an intense ring current or the storm-time radiation belt in the magnetosphere" [Akasofu, 1968, p. 5]. Although recent ENA observations from the Imager for Magnetopause-to-Aurora Global Exploration (IMAGE) spacecraft have shown that highenergy protons (of energies $>60 \mathrm{keV}$ ) and oxygen ions contribute more significantly to ring current than protons at energies 10-60 keV [Mitchell et al., 2003; P. C:son Brandt et al., IMAGE/HENA: Pressure and current distributions during the 1 October 2002 storm, submitted to Advances in Space Research, 2003], the core of Akasofu's idea is still applicable. During substorm expansion phases the oxygen ion outflows from the high-latitude ionosphere are an important oxygen ion supplement. When there is a lack of substorm expansion phases, the oxygen ion density will be low in the trapping region. Therefore ring current intensification might be weak. This result is also consistent with McFadden et al.'s [2001] conclusion based on the analysis of ion outflow data from the Fast Auroral Snapshot (FAST) spacecraft. They asserted that without substorm ion outflows, the plasma sheet density is relatively modest so that only a minor effect in Dst can result from the convection.

[24] The second possible explanation of the low-intensity magnetic storms is that penetration of the plasma flow in the tail to the inner magnetosphere may have been choked off. In general, the release of plasma from the magnetotail to the inner magnetosphere and into the ring current is constrained because the plasma is frozen in the magnetic fields, and the plasma transport is adiabatic. The differential flux tube
Table 1. Calculated and Observed $\Phi_{\mathrm{pc}}$ (in 1223-1823 UT)

\begin{tabular}{lcccc}
\hline & \multicolumn{3}{c}{$\Phi_{\mathrm{pc}}, \mathrm{kV}$} \\
\cline { 2 - 5 } & Mean & Media & Maximum & Minimum \\
\hline$\Sigma=5 \mathrm{~S}$ & 119 & 120 & 131 & 100 \\
$\Sigma=10 \mathrm{~S}$ & 91 & 92 & 101 & 80 \\
SuperDARN & 69 & 69 & 78 & 61 \\
\hline
\end{tabular}

volume is given by the path integral of $B$ along the field line (i.e., $V=\int d s / B$ ). The volume decreases strongly near Earth due to the $1 / B$ dependence. Since $p V^{\gamma}$ has to be constant (to keep adiabaticity), the pressure would increase even more dramatically. Hence the massive buildup of plasma pressure should prevent the flow and stop further circulation if there are not frequent substorm expansion phases to release the magnetic stress [Erickson and Wolf, 1980; Daglis et al., 1999]. In the 15 July event, the substorm-related dipolarization in the near tail might not have occurred (or was very weak), which implies that there was no large-scale reconnection taking place in the tail current sheet. Thus the flux tube volume could not be reduced (such as in the way shown in Figure 9 of Daglis et al. [1999]). Consequently, the plasma flow proceeding into the storm-time ring current region $(L \sim 3-5)$ has been choked. Steady convection might still take place, but the return of magnetic flux to the dayside mainly takes place through the outer magnetosphere. In this way, ring current will not be built up significantly. An alternative scenario could be that the shielding electric field builds up with time, preventing deep magnetospheric convection [Rostoker, 1996]. Thus potential ring current particles could not be brought closer to the Earth where they can be trapped. The absence of substorm expansion phases during the 15 July 1997 event is in agreement with this hypothesis. The plasma cannot get closer to the Earth (i.e., stagnated in terms of the earthward flow velocity), and all flow in the stagnation region was then azimuthal.

[25] The third possible explanation is that the magnetospheric convection was retarded. The apparent $\Phi_{\mathrm{pc}}$ saturation (Figure 7) is the evidence. To check the polar cap potential drop induced by the solar wind $E_{y}$, we have calculated $\Phi_{\mathrm{pc}}$ for the 15 July 1997 event based on the following equation (equation (13) in the work of Siscoe et al. [2002]):

$$
\Phi_{\mathrm{pc}}=\frac{57.6 E_{y} P_{s w}^{1 / 3} D^{4 / 3} F(\theta)}{P_{s w}^{1 / 2} D+0.0125 \xi \Sigma E_{y} F(\theta)},
$$

where $P_{s w}$ is the solar wind ram pressure defined as $P_{s w}=$ $1.16 \rho_{p} V_{s w}^{2}$. Here we assumed a value for $\mathrm{N}_{\mathrm{H}_{\mathrm{e}}^{++}}=4 \% \mathrm{~N}_{\mathrm{H}^{+}}$; the $\rho_{p}$ is the mass density of protons. $D$ is normalized to 1 for the Earth dipole field. The $\theta$ is the clock angle of IMF and $F(\theta)=0 / 1$ for northward/southward IMF. The $\xi$ is a dimensionless coefficient between 3 and 4 . The $\Sigma$ is the height-integrated Pedersen ionospheric conductivity and is set to be 5 and $10 \mathrm{~S}$ in our calculations. Detailed description for the above parameters can be found in the work of Hairston et al. [2003]. A comparison between calculated results from equation (1) and the SuperDARN observations is shown in Table 1. The calculations were made for the interval 1223-1823 UT when the average IMF $B_{z}$ was $-10.3 \mathrm{nT}$. The result shows that the expected $\Phi_{\mathrm{pc}}$ is $\sim 30-$ 
$70 \%$ higher than the SuperDARN-measured $\Phi_{\mathrm{pc}}$ during this particular event.

[26] The above low $\Phi_{\mathrm{pc}}$ can result from a lower subsolar reconnection rate that could be led by smooth or steady southward interplanetary magnetic fields. Song and Lysak [2001] have shown that the kinetic energy carried by fast mode wave packets, which can be produced by a change in IMF, increases the reconnection occurrence and rate. During magnetic clouds, IMF is relatively constant. Therefore the subsolar reconnection can be scarce. So the polar cap potential drop will be low such as that during this 15 July 1997 event.

\section{Discussion}

[27] The examination of energetic particle data from the LANL geosynchronous satellite has shown that the magnetic storm was less intense (i.e., less negative) when there was a lack of substorm injections. One possible scenario for this result is that during steady nightside reconnection, closed magnetic field lines might be convected back to the dayside magnetosphere in a continuous and steady way for large timescales (few hours or more) and on an average sense. During this convection, plasma moves earthward without impulsive "unloadings" that can cause energetic particle dispersionless injections at the geosynchronous orbit and substorm auroral expansions on the ground [Liou et al., 2001]. What might happen is that short bursty flows at $\sim 1$-min timescale with $\sim 10$-min periods occur [Angelopoulos et al., 1992], which have been considered as a tail source of auroral patches [Angelopoulos et al., 1997; Lyons et al., 1999; Sergeev et al., 1999; Sandholt and Farrugia, 2001]. Therefore "quasi-steady" convection might be a more appropriate description for this process (i.e., the convection is steady on a large timescale but bursty on a small scale).

[28] Aurorae observed by the Polar UVI during the main phase have been examined as well. A comparison between Figures 2 and 4 has shown that the aurora associated with a substorm expansion phase was mainly located in the midnight sector. Significant poleward, eastward, and westward auroral expansions occurred during the substorm expansion phase as the $A L$ indices decreased abruptly. In contrast, the aurora associated with the ring current intensification on 15 July 1997, when there was a lack of substorm expansion phases, was mainly composed of transient intense northsouth oriented auroral patches and torches along the whole nightside auroral oval. Those auroral patches and torches in the postmidnight region appeared to drift eastward and left an auroral gap near midnight. The common signature of the two events is that the auroral intensity increased when the $A L$ index decreased, and the auroral intensity decreased when $A L$ increased regardless of whether the ring current was being intensified. This implies that the $A L$ index and auroral activity depict more closely the high-latitude geomagnetic and current activity.

[29] Steady magnetospheric convection has been detected in the ionosphere and in the magnetotail [Sergeev et al., 1996, 2001, and references therein], although there are arguments in theory whether a steady convection can really take place in the tail [Erickson and Wolf, 1980; Kivelson and Spence, 1988; Pritchett and Coroniti, 1990; Erickson, 1992].
Criteria for a steady magnetospheric convection include a stable southward IMF $B_{z}$ (longer than 4-6 hours), $A E \geq$ $200 \mathrm{nT}$, no substorm signatures (such as Pi2 pulsations and negative magnetic bays) and no current sheet disruption or plasmoid in the near-Earth magnetotail [Sergeev et al., 1996]. Although there were no observations from the magnetotail during the 15 July 1997 event, auroral images from the Polar UVI can provide some information about the magnetotail indirectly. Sauvaud [1992] found that the lobe magnetic flux is reduced by $\sim 20-30 \%$ during substorm expansive phases. If there were substorm expansion phases during the 15 July 1997 event, we would expect a similar amount of shrinkage of the polar cap area. The fact is that the polar cap did not shrink but expanded as shown in Figure 4 during the ring current intensification. We, therefore, conclude that there was no abrupt decrease of the lobe magnetic flux content due to current sheet disruptions or plasmoid releases that could lead to substorm expansion onsets. Therefore the 15 July 1997 event is very similar in character to a steady magnetospheric convection event.

[30] During the magnetic storm main phase from 1200 to 2100 UT, the ring current was very asymmetric with ASY-H at $\sim 80 \mathrm{nT}$ during 1500-1700 UT (not shown is this paper). This signature can also be seen in magnetic field stack plots of eight individual stations that were used in the $A F$ index calculation (W. Sun, private communication, 2003). In general, during storm main phases the ring current is asymmetric especially for those storms caused by interplanetary magnetic clouds [Kozyra et al., 2002]. The contribution of the asymmetric component is higher than $80 \%$ [Liemohn et al., 2001]. One can expect that during main phases "only one ring current exists and this is an asymmetric one" [Grafe, 1999].

\section{Summary and Conclusion}

[31] In this paper we have studied a ring current intensification event that was driven by a magnetic cloud on 15 July 1997. The SYM-H minimum of the storm was $-47 \mathrm{nT}$, and the $A L$ minimum was $-930 \mathrm{nT}$ during the ring current intensification. The observations from the SuperDARN radars, the ground-based magnetometers, and the geosynchronous satellite support the speculation that the magnetosphere during the ring current intensification, when there was a long interval ( $\sim 8$ hours) of continuously southward IMF, might be in a state of quasi-steady convection during which the typical substorm expansion phases were scarce or unexpectedly weak. The presence of an $\sim 8$-hour interval of intense negative bay (Figure 5) was characterized by the continuously high polar cap electric potential drop, the steady increase of field-aligned currents and ENA flux (Figure 3), and a lack of energetic particle injections at the geosynchronous orbit (Figure 6). These effects are all consistent with enhanced quasi-steady convection, rather than intermittent impulsive onsets of transient processes during substorm expansion phases.

[32] In conclusion, under a continuous southward IMF during 15 July 1997 the ring current intensification was directly driven by a magnetospheric convection during which the energy release from the near-Earth tail was probably quasi-steady rather than the large-scale impulsive unloading that leads to substorm expansion phase onsets. 
The ring current intensification was relatively weak (i.e., less negative in SYM-H), which might be due to a low ion density in the plasma sheet, a choked penetration of the plasma flow to the inner magnetosphere, or a retarded magnetospheric convection due to reduced dayside magnetopause reconnection. The third possibility is quite intriguing and will be followed up by further studies.

[33] Acknowledgments. Portions of this research were performed at the Jet Propulsion Laboratory, California Institute of Technology, under contract with National Aeronautics and Space Administration. The work of G. Rostoker was supported by the Natural Sciences and Engineering Research Council of Canada. WDC-C2, at Kyoto, Japan, provided the ground-based $A L, A U$, and SYM-H indices. K. Ogilvie and R. P. Lepping provided the Wind SWE and MFI data. Operation of the SuperDARN radars in the Northern Hemisphere is supported by the national funding agencies of the United States, Canada, United Kingdom, France, and Japan. We acknowledge the support of NASA grant NAG5-10902 (JMR). CANOPUS was constructed and is operated by the Canadian Space Agency. The geomagnetic data from stations of TIK and CHD are part of the $210 \mathrm{MM}$ meridian line of magnetic observatories operated by the CPMN project, Kyushu University, and the Solar-Terrestrial Environment Laboratory, Nagoya University. The geomagnetic data from Poker Flat are contributed by GIMA managed by the Geophysical Institute of the University of Alaska.

[34] Arthur Richmond thanks Michael G. Henderson and Victor Sergeev for their assistance in evaluating this paper.

\section{References}

Ahn, B. H., B. A. Emery, H. W. Kroehl, and Y. Kamide, Climatological characteristics of the auroral ionosphere in terms of electric field and ionospheric conductance, J. Geophys. Res., 104, 10,031, 1999.

Akasofu, S.-I., The development of the auroral substorm, Planet. Space Sci., 12, 273, 1964.

Akasofu, S.-I., Polar and Magnetospheric Substorms, D. Reidel, Norwell, Mass., 1968.

Angelopoulos, V., et al., Bursty bulk flows in the inner central plasma sheet, J. Geophys. Res., 97, 4027, 1992.

Angelopoulos, V., et al., Magnetotail flow bursts: Association to global magnetospheric circulation, relationship to ionospheric activity and direct evidence for localization, Geophys. Res. Lett., 24, 2271, 1997.

Baker, D. N., A. J. Klimas, R. L. McPherron, and J. Buechner, The evolution from weak to strong geomagnetic activity: An interpretation in terms of deterministic chaos, Geophys. Res. Lett., 17, 41, 1990.

Baker, D. N., T. I. Pulkkinen, J. Buchner, and A. J. Klimas, Substorms: A global instability of the magnetosphere-ionosphere system, J. Geophys. Res., 104, 14,601, 1999.

Burton, R. K., R. L. McPherron, and C. T. Russell, An empirical relationship between interplanetary conditions and Dst, J. Geophys. Res., 80, 4204, 1975.

Chua, D., M. Brittnacher, G. Parks, G. Germany, and J. Spann, A new auroral feature: The nightside gap, Geophys. Res. Lett., 25, 2747, 1998.

Daglis, I. A., R. M. Thorne, W. Baumjohann, and S. Orsini, The terrestrial ring current: Origin, formation, and decay, Rev. Geophys., 37, 407, 1999.

Elphinstone, R. D., et al., The double oval UV auroral distribution, 1, Implications for the mapping of auroral arcs, J. Geophys. Res., 100, $12,075,1995 \mathrm{a}$.

Elphinstone, R. D., et al., The double oval UV auroral distribution, 2, The most poleward arc system and the dynamics of the magnetotail, J. Geophys. Res., 100, 12,093, 1995b.

Elphinstone, R. D., et al., Observations in the vicinity of substorm onset: Implications for the substorm process, J. Geophys. Res., 100, 7937, 1995c.

Erickson, G. M., A quasi-static magnetospheric convection model in two dimensions, J. Geophys. Res., 97, 6505, 1992.

Erickson, G. M., and R. A. Wolf, Is steady convection possible in the Earth's magnetotail?, Geophys. Res. Lett., 7, 897, 1980.

Farrugia, C. J., L. F. Burlaga, and R. P. Lepping, Magnetic clouds and the quiet-storm effect at Earth, in Magnetic Storms, Geophys. Monogr. Ser., vol. 98, edited by B. T. Tsurutani et al., p. 91, AGU, Washington, D. C., 1997.

Gonzalez, W. D., and B. T. Tsurutani, Criteria of interplanetary parameters causing intense magnetic storms $\left(\mathrm{D}_{\mathrm{st}}<-100 \mathrm{nT}\right)$, Planet. Space Sci., 35, 1101,1987

Gonzalez, W. D., B. T. Tsurutani, A. L. C. Gonzalez, E. J. Smith, F. Tang, and S.-I. Akasofu, Solar wind-magnetosphere coupling during intense magnetic storms (1978-1979), J. Geophys. Res., 94, 8835, 1989.
Gonzalez, W. D., J. A. Joselyn, Y. Kamide, H. W. Kroehl, G. Rostoker, B. T. Tsurutani, and V. M. Vasyliunas, What is a geomagnetic storm?, J. Geophys. Res., 99, 5771, 1994.

Grafe, A., Are our ideas about $D_{\text {st }}$ correct?, Ann. Geophys., 17, 1, 1999. Hairston, M. R., T. W. Hill, and R. A. Heelis, Observed saturation of the ionospheric polar cap potential during the 31 March 2001 storm, Geophys. Res. Lett., 30(6), 1325, doi:10.1029/2002GL015894, 2003.

Henderson, M. G., J. S. Murphree, and G. D. Reeves, The activation of the dusk-side and the formation of north-south aligned structures during substorms, paper presented at the Second International Conference on Substorms, Fairbanks, Alaska, 1995.

Henderson, M. G., J. S. Murphree, and G. D. Reeves, Are north-south aligned auroral structures the ionospheric manifestations of bursty bulk flows?, Geophys. Res. Lett., 25, 3737, 1998.

Henderson, M. G., et al., The evolution of north-south aligned auroral forms into auroral torch structures: The generation of omega bands and Ps6 pulsations via flow bursts, paper presented at the Sixth International Conference on Substorms, Seattle, Wash., 2002.

Hones, E. W., Jr., Transient phenomena in the magnetotail and their relation to substorms, Space Sci. Rev., 23, 393, 1979.

Iyemori, T., Time delay of the substorm onset from the IMF southward turning, J. Geomagn. Geoelectr., 32, 267, 1980.

Jorgensen, A. M., H. E. Spence, M. G. Henderson, G. D. Reeves, M. Sugiura, and T. Kamei, Global energetic neutral atom (ENA) measurements and their association with the Dst index, Geophys. Res. Lett., 24, 3173, 1997.

Kamide, Y., Is substorm occurrence a necessary condition for a magnetic storm?, J. Geomagn. Geoelectr., 44, 109, 1992.

Kan, J. R., L. Zhu, and S.-I. Akasofu, A theory of substorms: Onset and subsidence, J. Geophys. Res., 93, 5624, 1988.

Kivelson, M. G., and H. E. Spence, On the possibility of quasi-static convection in the quiet magnetotail, Geophys. Res. Lett., 15, 1541, 1988.

Klein, L. W., and L. F. Burlaga, Interplanetary magnetic clouds at $1 \mathrm{AU}$, J. Geophys. Res., 87, 613, 1982.

Kozyra, J. U., et al., Multistep Dst development and ring current composition changes during the 4-6 June 1991 magnetic storm, J. Geophys. Res., 107(A8), 1224, doi:10.1029/2001JA000023, 2002.

Liemohn, M. W., et al., Dominant role of the asymmetric ring current in producing the stormtime Dst*, J. Geophys. Res., 106, 10,883, 2001.

Liou, K., C.-I. Meng, P. T. Newell, A. T. Y. Lui, G. D. Reeves, and R. D. Belian, Particle injections with auroral expansions, J. Geophys. Res., 106, 5874, 2001.

Lui, A. T. Y., et al., Special features of a substorm during high solar wind dynamic pressure, J. Geophys. Res., 100, 19,095, 1995.

Lui, A. T. Y., R. W. McEntire, and K. B. Baker, A new insight on the cause of magnetic storms, Geophys. Res. Lett., 28, 3413, 2001.

Lyons, L. R., A new theory for magnetospheric substorms, J. Geophys. Res., 100, 19,069, 1995.

Lyons, L. R., G. T. Blanchard, J. C. Samson, R. P. Lepping, T. Yamamoto, and T. Moretto, Coordinated observations demonstrating external substorm triggering, J. Geophys. Res., 102, 27,039, 1997.

Lyons, L. R., et al., Association between geotail plasma flows and auroral poleward boundary intensifications observed by CANOPUS photometers, J. Geophys. Res., 104, 4485, 1999.

Lyons, L. R., J. M. Ruohoniemi, and G. Lu, Substorm-associated changes in large-scale convection during November 24, 1996 geospace environment modeling event, J. Geophys. Res., 106, 397, 2001.

McFadden, J. P., Y. K. Tung, C. W. Carlson, R. J. Strangeway, E. Moebius, and L. M. Kistler, FAST observations of ion outflow associated with magnetic storms, in Space Weather, Geophys. Monogr. Ser., vol. 125, edited by P. Song, H. J. Singer, and G. L. Siscoe, p. 413, AGU, Washington, D. C., 2001.

McPherron, R. L., T. Terasawa, and A. Nishida, Solar wind triggering of substorm onset, J. Geomagn. Geoelectr., 38, 1089, 1986.

Meng, C.-I., B. T. Tsurutani, K. Kawasaki, and S.-I. Akasofu, Cross-correlation analysis of the $A E$ index and interplanetary magnetic field $B_{z}$ component, J. Geophys. Res., 78, 617, 1973.

Mitchell, D. G., P. C:son Brandt, E. C. Roelof, D. C. Hamilton, K. C. Retterer, and S. Mende, Global imaging of $\mathrm{O}^{+}$from IMAGE/HENA, Space Sci. Rev., in press, 2003.

Nakamura, R., T. Oguti, T. Yamamoto, and S. Kokubun, Equatorward and poleward expansion of the auroras during auroral substorms, J. Geophys. Res., 98, 5743, 1993.

Nakamura, R., et al., Flow bursts and auroral activations: Onset timing and foot point location, J. Geophys. Res., 106, 10,777, 2001.

Perreault, P., and S.-I. Akasofu, A study of geomagnetic storms, Geophys. J. R. Astron. Soc., 54, 547, 1978.

Pritchett, P. L., and F. V. Coroniti, Plasma sheet convection and the stability of the magnetotail, Geophys. Res. Lett., 17, 2233, 1990. 
Pytte, T., R. L. McPherron, E. W. Hones Jr., and H. I. West Jr., Multiplesatellite studies of magnetospheric substorms: Distinction between polar magnetic substorms and convection-driven negative bays, J. Geophys. Res., 83, 663, 1978.

Reeves, G. D., et al., Using Los Alamos geosynchronous energetic particle data in support of other missions, in Satellite-Ground Based Coordination Source Book, Eur. Space Agency Spec. Publ., ESA-SP-1198, edited by M. Lockwood et al., pp. 263-272, Eur. Space Agency, Paris, 1997.

Rostoker, G., Phenomenology and physics of magnetospheric substorms, J. Geophys. Res., 101, 12,955, 1996.

Rostoker, G., Effects of substorms on the stormtime ring current index $D_{\text {st }}$, Ann. Geophys., 18, 1390, 2000.

Rostoker, G., et al., Magnetospheric substorms: Definition and signatures, J. Geophys. Res., 85, 1663, 1980.

Rostoker, G., M. Mareschal, and J. C. Samson, Response of dayside net downward field-aligned current to changes in the interplanetary magnetic field and to substorm perturbation, J. Geophys. Res., 87, 3489, 1982.

Rostoker, G., A. T. Y. Lui, C. D. Anger, and J. S. Murphree, North-south structures in the midnight sector auroras as viewed by the Viking imager, Geophys. Res. Lett., 14, 407, 1987.

Ruohoniemi, J. M., and K. B. Baker, Large-scale imaging of high-latitude convection with SuperDARN HF radar observations, J. Geophys. Res., 103, 20,797, 1998.

Russell, C. T., How northward turnings of the IMF can lead to substorm expansion onsets, Geophys. Res. Lett., 27, 3257, 2000.

Russell, C. T., R. L. McPherron, and R. K. Burton, On the cause of geomagnetic storms, J. Geophys. Res., 79, 1105, 1974.

Sandholt, P. E., and C. I. Farrugia, Multipoint observations of substorm intensifications: The high-latitude aurora and electron injections in the inner equatorial plasmasheet, Geophys. Res. Lett., 28, 483, 2001.

Sauvaud, J.-A., Characteristics of the cross-tail current disruption at substorm onset and associated particle acceleration, in Substorms 1, Eur. Space Agency Spec. Publ., ESA-SP-335, 243 pp., Paris, 1992.

Sergeev, V. A., R. J. Pellinen, and T. I. Pulkkinen, Steady magnetospheric convection: A review of recent results, Space Sci. Rev., 75, 551, 1996.

Sergeev, V. A., et al., Continuous activity and substorm activations during a weak magnetic storm (wind tail passage), in International Conference on Substorms-4, edited by S. Kokubun and Y. Kamide, 681 pp., Terra Sci., Tokyo, 1998.

Sergeev, V. A., K. Liou, C.-I. Meng, P. T. Newell, M. Brittnacher, G. Parks, and G. D. Reeves, Development of auroral streamers in association with localized injections to the inner magnetotail, Geophys. Res. Lett., 26, 417, 1999.

Sergeev, V. A., M. V. Kubyshkina, K. Liou, P. T. Newell, G. Parks, R. Nakamura, and T. Mukai, Substorm and convection bay compared: Auroral and magnetotail dynamics during convection bay, J. Geophys. Res., 106, 18,843, 2001.

Shepherd, S. G., and J. M. Ruohoniemi, Electrostatic potential patterns in the high latitude ionosphere constrained by SuperDARN measurements, J. Geophys. Res., 105, 23,005, 2000.
Siscoe, G. L., et al., Hill model of transpolar potencial saturation: Comparisons with MHD simulations, J. Geophys. Res., 107(A6), 1075, doi:10.1029/2001JA000109, 2002.

Song, Y., and R. L. Lysak, Towards a new paradigm: From a quasi-steady description to a dynamical description of the magnetosphere, Space Sci. Rev., 95, 273, 2001.

Sun, W., and S.-I. Akasofu, On the formation of the storm-time ring current belt, J. Geophys. Res., 105, 5411, 2000.

Sun, W., and S.-I. Akasofu, A new field-aligned current index $A F$ and its relation to the storm-time ring current and energetic neutral atom (ENA) emissions, Geophys. Res. Lett., 29(10), 1480, doi:10.1029/ 2002GL014762, 2002.

Torr, M. R., et al., A far ultraviolet imager for the international solarterrestrial physics mission, Space Sci. Rev., 71, 329, 1995.

Tsurutani, B. T., and C.-I. Meng, Interplanetary magnetic-field variations and substorm activity, J. Geophys. Res., 77, 2964, 1972.

Tsurutani, B. T., W. D. Gonzalez, F. Tang, S.-I. Akasofu, and E. J. Smith, Origin of interplanetary southward magnetic fields responsible for major magnetic storms near solar maximum (1978-1979), J. Geophys. Res., 93, 8519, 1988.

Tsurutani, B. T., X.-Y. Zhou, and W. D. Gonzalez, A lack of substorm expansion phases during magnetic storms induced by magnetic cloud, in The Storm-Substorm Relationship, Geophys. Monogr. Ser, edited by Y. Kamide et al., AGU, Washington, D. C., in press, 2003.

Yumoto, K., et al., The STEP 210 magnetic meridian network project, J. Geomagn. Geoelectr., 8, 1297, 1996.

Yumoto, K., et al., Characteristics of Pi2 magnetic pulsations observed at the CPMN stations: A review of the STEP results, Earth Planets Space, $53,981,2001$.

J. K. Arballo, B. T. Tsurutani, and X.-Y. Zhou, Jet Propulsion Laboratory, California Institute of Technology, 4800 Oak Grove Drive, Pasadena, CA 91109-8099, USA. (xiaoyan.zhou@jpl.nasa.gov)

W. D. Gonzalez, Instituto Nacional de Pesquisas Espaciais (INPE), Caixa Postal 515, 12201-970 S. J. Dos Campos, São Paulo, Brazil.

Y. Kamide, Solar-Terrestrial Environment Laboratory, Nagoya University, Honohara 3-13, Toyokawa, Aichi-ken 442, Japan.

A. T. Y. Lui and J. M. Ruohoniemi, Applied Physics Laboratory, Johns Hopkins University, 11100 Johns Hopkins Road, Laurel, MD 20723, USA. G. K. Parks, Space Science Laboratory, University of California, Berkeley, Centennial and Grizzly Peak Blvd., Berkeley, CA 94720, USA. G. Reeves, Los Alamos National Laboratory, NIS-2, Mail Stop D-436, Los Alamos, NM 87545, USA.

G. Rostoker, Department of Physics, Faculty of Science, University of Alberta, 412 Avadh Bhatia Physics Laboratory, Edmonton, Alberta, Canada T6G $2 \mathrm{~J} 1$.

W. Sun, Geophysical Institute, University of Alaska, Fairbanks, P. O. Box 757320, Fairbanks, AK 99775-7320, USA. 